\title{
Activador tisular del plasminógeno recombinante para el tratamiento de la vegetación intracardíaca en un lactante de muy bajo peso al nacer \\ Recombinant tissue plasminogen activator treatment for intracardiac vegetation in a very low birth weight infant
}

\section{Dr. Abdurrahman A. Ozdemir}

\begin{abstract}
RESUMEN
Lasnuevasopciones de tratamiento prolonganlahospitalización y aumentan las infecciones intrahospitalarias bacterianas y fúngicas, pero también mejoran la sobrevida de los recién nacidos hospitalizados en la unidad de cuidados intensivos neonatales. Las infecciones fúngicas invasivas en neonatos están asociadas con una morbimortalidad significativa. También pueden diseminarse a órganos específicos y causar endocarditis, endoftalmitis, artritis séptica, nefropatía obstructiva y meningitis. En el caso de la endocarditis, se recomiendan tratamientos antimicóticos sistémicos agresivos y, en algunos casos, la intervención quirúrgica del neonato.

Informamos el caso de un lactante prematuro, de bajo peso al nacer, con vegetación intracardíaca. Esta es una complicación rara y potencialmente mortal de infecciones fúngicas invasivas. El paciente recibió tratamiento con caspofungina y un activador tisular del plasminógeno recombinante, en vez de una intervención quirúrgica.

Palabras clave: micótico, endocarditis, activador tisular recombinante, caspofungina.
\end{abstract}

http:/ / dx.doi.org/10.5546/ aap.2017.e307

Texto completo en inglés:

http: / / dx.doi.org/10.5546/ aap.2017.eng.e307

Cómo citar: Ozdemir AA. Activador tisular del plasminógeno recombinante para el tratamiento de la vegetación intracardíaca en un lactante de muy bajo peso al nacer. Arch Argent Pediatr 2017; 115(5):e307-e310 a. Departamento de Pediatría, División de Neonatología, Hospital Médico de Estambul, Estambul, Turquía.

Correspondencia:

Dr. Abdurrahman A. Ozdemir: avarozdemir@gmail.com

Financiamiento: Ninguno.

Conflicto de intereses: Ninguno que declarar.

Recibido: 14-1-2017

Aceptado: 6-5-2017

\section{INTRODUCCIÓN}

Las nuevas opciones de tratamiento prolongan la hospitalización y aumentan las infecciones intrahospitalarias bacterianas y fúngicas, pero también mejoran la sobrevida de los recién nacidos hospitalizados en la unidad de cuidados intensivos neonatales (UCIN). Candida spp. es la tercera causa más frecuente de infecciones de aparición tardía en recién nacidos con muy bajo y extremadamente bajo peso al nacer; su incidencia varía entre el 2,6\% y el $10 \%$ y entre el 5,5\% y el $20 \%$, respectivamente. Se ha informado que en los recién nacidos prematuros, la tasa de mortalidad por infecciones fúngicas invasivas es de hasta $20 \%-60 \% .^{1-3}$

En los recién nacidos, la endocarditis fúngica es una complicación potencialmente mortal de las infecciones invasivas por Candida spp. Se recomienda la administración de un tratamiento antimicótico sistémico a largo plazo y, en algunos casos, recurrir a la intervención quirúrgica. ${ }^{4,5}$ Este trabajo informa el caso de un recién nacido con muy bajo peso al nacer, con vegetación fúngica intracardíaca, que fue tratado con éxito con caspofungina y un activador tisular del plasminógeno recombinante (ATPr).

\section{A PROPÓSITO DE UN CASO}

Recién nacido varón, prematuro, que nació a las 28 semanas de gestación por sufrimiento fetal. Su peso al nacer fue de $1030 \mathrm{~g}$; la madre era secundípara, de 30 años de edad. El paciente fue trasladado a la UCIN y después de ser intubado por síndrome de dificultad respiratoria recibió tratamiento temprano con surfactante. Tras la inserción de una vía umbilical, se administraron ampicilina y gentamicina, ya que no era posible descartar una septicemia. Se inició profilaxis antimicótica con fluconazol debido al aumento de los factores de riesgo. Al tercer día, el paciente presentó hemorragia pulmonar por lo que se interrumpió la alimentación enteral. Se administraron un surfactante y plasma congelado en fresco. Se inició la alimentación 
enteral mínima el día 8. Al día siguiente el estado del paciente empeoró presentando distensión abdominal. La radiografía directa y la ecografía mostraron dilatación de las asas intestinales, en particular en la región ileocólica. En ese momento, los datos de laboratorio mostraron valores de leucocitos de $17460 / \mathrm{mm}^{3}$, trombocitos de $107000 / \mathrm{mm}^{3}$, nivel normal de PCR $(0,3 \mathrm{mg} /$ dl) e hiperglucemia $(159 \mathrm{mg} / \mathrm{dl})$. Se realizó el diagnóstico de enterocolitis necrotizante y se cambiaron los antibióticos a teicoplanina, cefoperazona-sulbactam y metronidazol; la alimentación enteral se interrumpió nuevamente. El día 14 se extubó al paciente y se inició la presión continua positiva en las vías respiratorias. Después de 3 días, se detectaron apnea y acidosis metabólica y el paciente fue reintubado. Se realizaron pruebas diagnósticas de septicemia y en el hemocultivo se identificó C. parapsilosis. En consecuencia, se retiró la vía umbilical y se inició el tratamiento con anfotericina B convencional. Las ecografías craneales y abdominales, la ecocardiografía y el examen oftalmológico resultaron normales. La siguiente semana, Candida parapsilosis continuó multiplicándose en los hemocultivos y al realizar una ecocardiografía se identificó una masa de 7,7 mm de largo y $7,3 \mathrm{~mm}$ de ancho (aspergiloma) en la aurícula derecha (Figura 1). El paciente también presentó hinchazón de los miembros inferiores debido a la obstrucción del flujo venoso. Como consecuencia, se agregó acetato de caspofungina $(2 \mathrm{mg} / \mathrm{kg} /$ día) a la anfotericina $B$ convencional para el tratamiento combinado. Después de 8 días, no se detectó proliferación fúngica en los cultivos. La anfotericina $\mathrm{B}$ y la caspofungina se administraron durante 6 semanas. Los hemocultivos de control

FIGURA 1. Ecocardiografía que muestra la vegetación en la aurícula derecha antes del tratamiento con ATPr

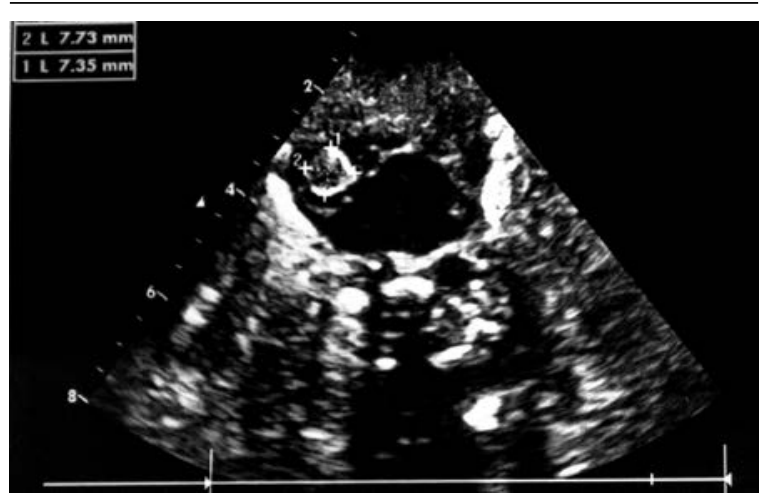

siguieron arrojando resultados negativos. No obstante, durante los días siguientes, no se modificaron el tamaño de la vegetación ni la hinchazón de las extremidades inferiores. Por lo tanto, se decidió usar el ATPr para la trombólisis. Una vez que el Comité de Ética aprobó el protocolo de tratamiento y que los padres firmaron el consentimiento informado, se inició la infusión de ATPr a 0,3 mg/ $\mathrm{kg} /$ hora durante 6 horas, después de haber administrado plasma congelado en fresco al paciente. Antes del tratamiento, la ecografía de cráneo fue normal y los parámetros de coagulación iniciales (TP, TTPa, RIN y fibrinógeno) estaban dentro del rango normal. La infusión de ATPr se repitió durante 3 días bajo supervisión estricta. Las ecocardiografías seriadas revelaron que el tamaño de la vegetación disminuyó a 2,1 $\mathrm{mm}$ x 2,5 mm y no se observaron complicaciones (Figura 2). Después del tratamiento con ATPr se resolvió la obstrucción venosa y desapareció la hinchazón de los miembros inferiores. El paciente recibió el alta el día 84 desde la fecha de admisión y actualmente el Departamento de Cardiología Pediátrica es responsable de su seguimiento.

\section{DISCUSIÓN}

En los recién nacidos, la causa más frecuente de infecciones fúngicas es por Candida spp. Candida albicans (C. albicans) y Candida parapsilosis (C. parapsilosis) son responsables de la mayoría de las infecciones invasivas por Candida en las UCIN. ${ }^{1,6}$

Los factores de riesgo que aumentan la frecuencia de las infecciones fúngicas son muchos: la prematurez, el bajo peso al nacer, la intubación prolongada, el retraso de la alimentación enteral, el

FIGURA 2. Ecocardiografía que muestra la reducción de la vegetación después de 1 semana de tratamiento con ATPr

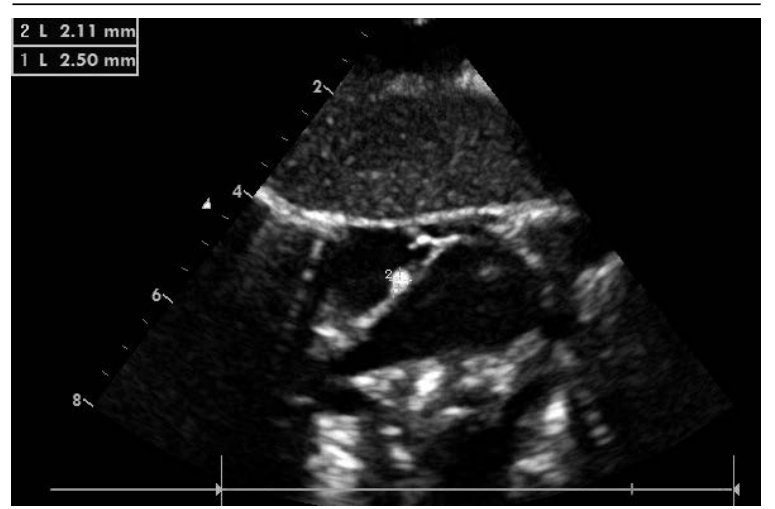


uso de antibióticos de amplio espectro, corticoides y bloqueadores de $\mathrm{H} 2$, las cirugías, la enterocolitis necrosante y el uso prolongado de una vía central. ${ }^{7}$ Casi todos estos factores de riesgo estuvieron presentes en nuestro caso y en el hemocultivo se aisló C. parapsilosis.

Candida spp. puede diseminarse a órganos específicos y causar endocarditis, endoftalmitis, nefropatía obstructiva y meningitis. Se ha publicado que la frecuencia de compromiso cardíaco en las infecciones fúngicas invasivas varía entre el 5\% y el 15\%, y la mortalidad es muy alta. Por lo tanto, el diagnóstico precoz y el manejo agresivo son fundamentales para que el tratamiento sea satisfactorio. La endocarditis fúngica puede estar asociada con la presencia de vegetaciones intracardíacas en el corazón derecho en los recién nacidos. En especial, el daño endotelial y las vías centrales contribuyen a la formación de endocarditis y trombos. Cuando se determina la presencia de candidemia debe retirarse la vía venosa central y deben realizarse una ecocardiografía, una oftalmoscopia y el análisis del líquido cefalorraquídeo y de orina. ${ }^{1,4,5,8}$ Una vez detectada la presencia de Candida spp. se inició el tratamiento antimicótico y se retiró la vía umbilical. Se evaluaron todos los aparatos y sistemas en busca de diseminación a órganos específicos y la ecocardiografía reveló la presencia de una vegetación fúngica en la aurícula derecha.

El tratamiento de la candidiasis invasiva requiere el uso prolongado de antimicóticos como el fluconazol, formulaciones de anfotericina B (convencional y liposomal) o equinocandinas (micafungina y caspofungina) durante al menos 4 a 6 semanas o hasta 2 semanas después de 2 hemocultivos negativos. El fluconazol es un agente fungistático de espectro reducido; por lo tanto, para el tratamiento inicial de la endocarditis por Candida spp. en recién nacidos se recomiendan las formulaciones de anfotericina $B$ y las equinocandinas. Sin embargo, en los recién nacidos no se ha definido claramente cuál es la dosis adecuada de caspofungina que deben recibir. La dosis recomendada de caspofungina (25 mg/ m²/ día o 1-2 $\mathrm{mg} / \mathrm{kg} /$ día) para uso neonatal se basa en una pequeña serie de casos. ${ }^{9-11}$ Los agentes antimicóticos podrían combinarse para el tratamiento de la endocarditis. En un estudio de revisión, Pana y col. informaron que el tratamiento antimicótico combinado estaba asociado con una menor mortalidad que la monoterapia. ${ }^{5}$ En nuestro paciente, se administró anfotericina B convencional como tratamiento inicial. En los días siguientes, Candida spp. continuó multiplicándose en los hemocultivos; por lo tanto, se agregó la caspofungina para el tratamiento combinado. Después de 8 días, no se aisló Candida spp. en los cultivos. La caspofungina y la anfotericina $B$ se administraron durante 6 semanas.

En nuestro paciente, no se observó un cambio en el tamaño de la vegetación intracardíaca y la obstrucción del flujo sanguíneo, aunque los cultivos fueron negativos con el tratamiento con caspofungina. En estos casos, es necesario usar agentes antimicóticos conjuntamente con la extirpación quirúrgica del trombo para el tratamiento de la endocarditis fúngica. Sin embargo, la decisión de intervenir quirúrgicamente a un recién nacido prematuro es difícil, debido a la alta mortalidad por la inestabilidad clínica y el muy bajo peso al nacer. ${ }^{1,4,5}$ En consecuencia, optamos por un tratamiento trombolítico en vez de una intervención quirúrgica. La uroquinasa, la estreptoquinasa y los ATPr se usan para el tratamiento trombolítico en niños y adultos. No obstante, la uroquinasa y la estreptoquinasa generalmente no son la alternativa preferida durante el período neonatal debido a la menor especificidad de la fibrina y la alta antigenicidad. ${ }^{12}$ El ATPr es una proteína recombinante que cataliza la conversión de plasminógeno a plasmina. Tiene algunas ventajas, tal como la baja antigenicidad, la activación directa del plasminógeno, la fibrinólisis sin causar proteólisis y una vida media breve, en comparación con la estreptoquinasa y la uroquinasa. ${ }^{13}$ Por lo tanto, decidimos usar ATPr para el tratamiento trombolítico, aunque existen datos limitados sobre el tratamiento con este agente de prematuros con trombos fúngicos intracardíacos.

En general, el ATPr se usó en dosis de 0,1$0,6 \mathrm{mg} / \mathrm{kg} /$ hora durante 6 a 12 horas y se repitió durante 3 días, aunque en los diferentes estudios la dosis y la duración del tratamiento varían. , $^{83-15}$ Antes del tratamiento trombolítico, es necesario evaluar a los pacientes para determinar si hay contraindicaciones, entre ellas convulsiones dentro de las 48 horas, hemorragia activa, deficiencia de la coagulación, procedimientos invasivos dentro de los 3 días, trombocitopenia, niveles bajos de fibrinógeno, hipertensión y septicemia grave. ${ }^{15}$ En nuestro caso, no había contraindicaciones al tratamiento trombolítico, por lo cual comenzamos con la administración de ATPr después de haber administrado 
plasma congelado en fresco para aportar suficiente plasminógeno. Al final de 3 días, la ecocardiografía mostró que el tamaño de la vegetación había disminuido notablemente y el tratamiento con ATPr se interrumpió. Por lo tanto, el tratamiento de la vegetación intracardíaca con ATPr, en dosis y duración promedio, fue satisfactorio y, en nuestro caso, no se observaron complicaciones durante o después del tratamiento.

En conclusión, sugerimos que la caspofungina podría ser una opción alternativa de tratamiento en recién nacidos prematuros con endocarditis por Candida spp. resistente a otros antimicóticos. Asimismo, la vegetación fúngica pudo tratarse satisfactoriamente con ATPr. Este caso muestra que el ATPr podría usarse, bajo estricta supervisión, para el tratamiento de trombos intracardíacos, y que podría ser una importante alternativa a la cirugía en recién nacidos de alto riesgo. Sin embargo, es necesario realizar estudios más amplios y prospectivos para determinar la dosis y duración seguras del tratamiento con ATPr de recién nacidos prematuros.

\section{REFERENCIAS}

1. Kaufman DA, Fairchild KD. Clinical microbiology of bacterial and fungal sepsis in very-low-birth-weight infants. Clin Microbiol Rev 2004;17(3):638-80.

2. Zaoutis TE,HeydonK, Localio R, etal.Outcomesattributable to neonatal candidiasis. Clin Infect Dis 2007;44(9):1187-93.

3. Montagna MT, Lovero G, De Giglio O, et al. Invasive fungal infections in neonatal intensive care units of southhern Italy: a multicentre regional active surveillance (AURORA project). J Prev Med Hyg 2010;51(3):125-30.

4. NoyolaDE,FernandezM,MoylettEH, etal.Ophthalmologic, visceral, and cardiac involvement in neonates with candidemia. Clin Infect Dis 2001;32(7):1018-23.

5. Pana ZD, Dotis J, Iosifidis E, et al. Fungal endocarditis in neonates: A review of seventy-one cases (1971-2013). Pediatr Infect Dis J 2015;34(8):803-8.

6. López Sastre JB, Coto Cotallo GD, Fernández Colomer B. Neonatal invasive candidiasis: a prospective multicenter study of 118 cases. Am J Perinatol 2003;20(3):153-63.

7. SwansonJR, GurkaMJ, KaufmanDA.Risk factors forinvasive fungal infection in prematüre infants: Enhancing a targeted prevention approach. J Pediatric Infect Dis Soc 2014;3(1): 49-56.

8. Babayigit A, Cebeci B, Buyukkale G, et al. Treatment of neonatal fungal infective endocarditis with recombinant tissue plasminogen activator in a low birth weight infant case report and review of the literature. Mycoses 2015;58(10):578-81.

9. Santolaya ME, Alvarado Matute T, de Queiroz Telles F, et al. Recommendations for the management of candidemia in neonates in Latin America. Latin America Invasive Mycosos Network. Rev Iberoam Micol 2013;30(3):158-70.

10. Hope WW, Castagnola E, Groll AH, etal. ESCMID guideline for the diagnosis and management of Candida diseases 2012: prevention and management of invasive infections in neonates and children caused by Candida spp. Clin Microbiol Infect 2012;18 (Sippl 7):38-52.

11. Lestner JM, Smith PB, Cohen-Wolkowiez M, et al. Antifungal agents and therapy for infants and children with invasive fungal infections: a pharmacological perspective. Br J Clin Pharmacol 2013;75(6):1381-95.

12. Veldman A, Nold MF, Michel-Behnke I. Thrombosis in the critically ill neonate: incidence, diagnosis, and management. Vasc Health Risk Manag 2008;4(6):1337-48.

13. Hartmann J, Hussein A, Trowitzsch E, et al. Treatment of neonatal thrombus formation with recombinant tissue plasminogen activator: six years experience and review of the literature. Arch Dis Child Fetal Neonatal Ed 2001; 85(1):F18-22.

14. Ferrari F, Vagnarelli F, Gargano G, et al. Early intracardiac thrombosis in preterm infants and thrombolysis with recombinant tissue type plasminogen activator. Arch Dis Child Fetal Neonatal Ed 2001;85(1):F66-9.

15. Aydin B, Beken S, Dilli D, et al. Fibrinolytic therapy of thrombosis in 27 newborns followed-up in neonatal intensive care unit. Pediatr Hematol Oncol 2013;30(8):705-16. 